\title{
Synthesis, Spectral Characteristics, and Some Properties of Methylammonium Sulfamate Monohydrate. A New Route to Sulfamic Acid Derivatives
}

\author{
R. E. Khoma ${ }^{a, b}$, A. V. Mazepa ${ }^{c}$, V. O. Gelmboldt ${ }^{d, b}$, A. A. Shestaka ${ }^{b}$, \\ L. V. Koroeva ${ }^{b}$, M. D. Tsapko ${ }^{e}$, and A. A. Ennan ${ }^{b}$ \\ ${ }^{a}$ Mechnikov National University, Dvoryanskaya ul. 2, Odessa, 65026 Ukraine \\ ${ }^{b}$ Physicochemical Institute for Human and Environmental Protection, Ministry of Education and Science \\ and National Academy of Sciences of Ukraine, ul. Preobrazhenskaya, Odessa, 65026 Ukraine \\ ${ }^{c}$ Bogatskii Physicochemical Institute, National Academy of Sciences of Ukraine, \\ Lustdorfskaya doroga 86, Odessa, 65080 Ukraine \\ ${ }^{d}$ Odessa State Medical University, per. Valikhovskogo 2, Odessa, 65026 Ukraine \\ e Shevchenko National University, Volodymyrska vul. 64, Kiev, 01033 Ukraine \\ Received December 30, 2009
}

\begin{abstract}
Redox transformations of the products of reactions of the $\mathrm{CH}_{3} \mathrm{C}(\mathrm{S}) \mathrm{NH}_{2}-\mathrm{SO}_{2}-\mathrm{H}_{2} \mathrm{O}$ system components yield methylammonium sulfamate monohydrate $\left[\mathrm{CH}_{3} \mathrm{NH}_{3}\right]^{+}\left[\mathrm{OSO}_{2} \mathrm{NH}_{2}\right]^{-} \cdot \mathrm{H}_{2} \mathrm{O}$ and elemental sulfur. The synthesized compound was characterized by IR, ${ }^{1} \mathrm{H}$ and ${ }^{13} \mathrm{C} \mathrm{NMR}$, and mass spectroscopy and some of its properties were studied.
\end{abstract}

DOI: $10.1134 / \mathrm{S} 0036023610120016$

It is known that sulfamic acid $\left(\mathrm{HOSO}_{2} \mathrm{NH}_{2}\right)$, its salts and derivatives are used as medical drugs [1], disinfectants [2], herbicides [3], and reagents and catalysts of organic reactions [4-6]. Sulfamic acid is produced using corrosive compounds, for example, by the reaction of oleum with carbamide; $\mathrm{SO}_{3}$ with $\mathrm{NH}_{3}$ in anhydrous medium; sulfuryl chloride, $\mathrm{SO}_{2}$, and hydroxylamine [7].

This communication describes an original method for the synthesis of methylammonium sulfamate, which was prepared and characterized by Goodson [8]. Thioacetamide $\left(\mathrm{CH}_{3} \mathrm{C}(\mathrm{S}) \mathrm{NH}_{2}\right)$ and sulfur dioxide were used as the reactants, and water was used as the reaction medium.

\section{EXPERIMENTAL}

A suspension of thioacetamide $(0.075 \mathrm{~mol}, 5.63 \mathrm{~g})$ in water $(5.0 \mathrm{~mL})$ was placed into a $50-\mathrm{mL}$ reactor, cooled to $0^{\circ} \mathrm{C}$, and kept at this temperature for $30 \mathrm{~min}$. Then $\mathrm{SO}_{2}$ was bubbled through the suspension for $1 \mathrm{~h}$ at a flow rate of $50 \mathrm{~mL} \mathrm{~min}^{-1}$. This was accompanied by dissolution of thioacetamide with simultaneous formation of a finely dispersed white-yellow precipitate. On further storage of the reaction mixture for 2 to 3 days, additional precipitation took place. Recrystallization of the water-insoluble precipitate from benzene gave yellow crystals (I) (1.73 g). The decanted aqueous solution was concentrated in air at room temperature until white crystalline compound (II) formed
( $3.56 \mathrm{~g}$, yield $64.93 \%$ relative to $\mathrm{N}$ ). The product was purified by recrystallization from water.

The nitrogen, carbon, and hydrogen contents were determined using a CHN-analyzer; sulfur was quantified by the Schoeniger method [9]. The IR spectra were recorded on a Perkin-Elmer Spectrum BX II FTIR System spectrophotometer in the range of 4000$350 \mathrm{~cm}^{-1}$ (samples were prepared as $\mathrm{KBr}$ pellets); the ${ }^{1} \mathrm{H}$ and ${ }^{13} \mathrm{C}$ NMR spectra were recorded as a Bruker WM 400 radiospectrometer; EI mass spectra were run on an MX-1321 instrument (direct sample injection to the source; ionizing electron energy of $70 \mathrm{eV}$ ). The specific electrical conductivity of $10^{-3} \mathrm{M}$ solutions of compound II in anhydrous $\mathrm{CH}_{3} \mathrm{OH},\left(\mathrm{CH}_{3}\right)_{2} \mathrm{SO}$, $\mathrm{C}_{2} \mathrm{H}_{5} \mathrm{OH}$, and $\mathrm{CH}_{3} \mathrm{CN}$ and in distilled water was measured using an Expert 002 conductometer. The potentiometric measurement was carried out on a $\mathrm{pH}-150 \mathrm{M}$ $\mathrm{pH}$-meter

\section{RESULTS AND DISCUSSION}

According to mass spectrometry data, the yellowcolored crystals of $\mathbf{I}$ represent elemental sulfur: the mass spectrum of this product exhibits peaks for $\mathrm{S}_{8}^{+}$ ions $(m / z=256, I=7 \%)$ and $\mathrm{S}_{6}^{+}(m / z=192, I=8 \%)$, $\mathrm{S}_{5}^{+}(m / z=160 . I=16 \%), \mathrm{S}_{4}^{+}(m / z=128, I=18 \%), \mathrm{S}_{3}^{+}$ $(m / z=96, I=10 \%)$, and $\mathrm{S}_{2}^{+}(m / z=64, I=100 \%)$ fragment ions. 
Table 1. Wave numbers $\left(\mathrm{cm}^{-1}\right)$ of the absorption maxima in the IR spectra of thioacetamide and compound II

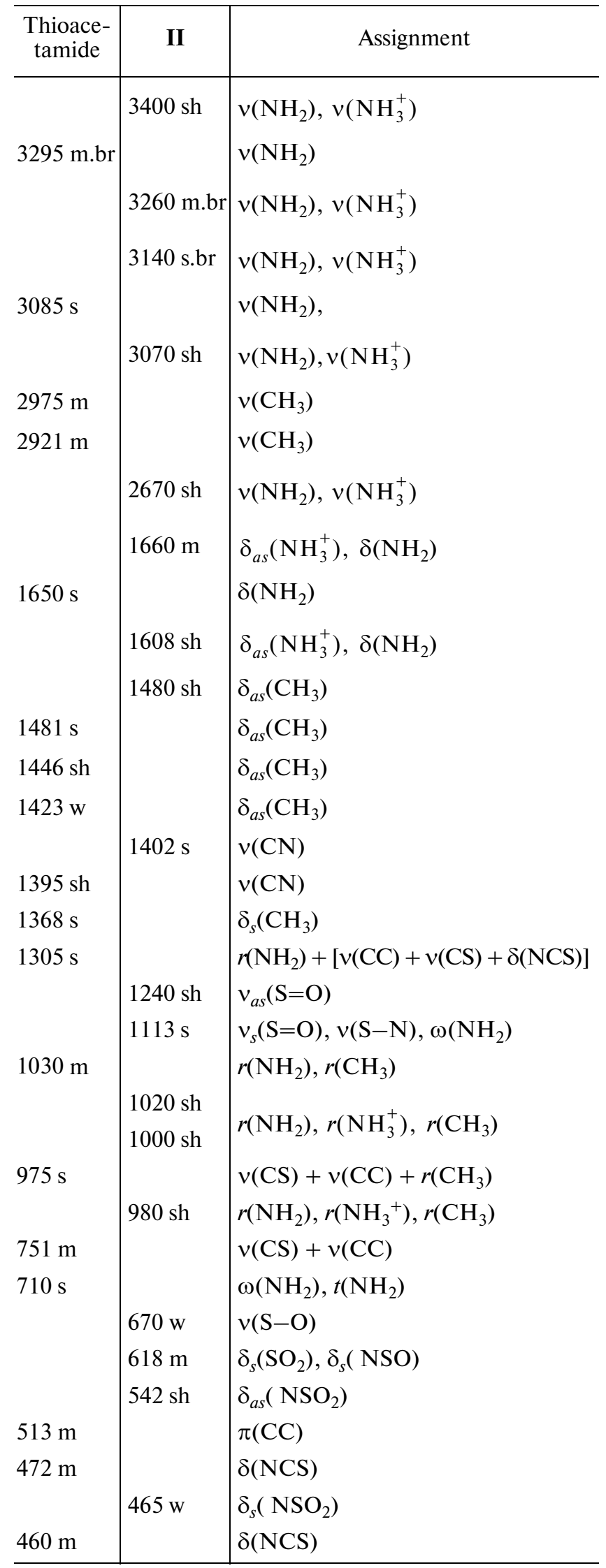

The composition of II according to elemental analysis data was as follows:

For $\mathrm{CH}_{10} \mathrm{~N}_{2} \mathrm{O}_{4} \mathrm{~S}$ anal. calcd. (\%): C, 8.22; $\mathrm{N}$, 19.17; S, 21.94; H, 6.90.

Found (\%): C, 7.89; N, 19.06; S, 22.32; H, 6.31.

The mass spectrum of II contains peaks with $m / z=$ $97, I=4 \%$ and $m / z=80, I=100 \%$, which were assigned to the $[\mathrm{M}]^{+}\left[\mathrm{H}_{3} \mathrm{NO}_{3} \mathrm{~S}\right]^{+}$molecular ion of sulfamic acid and the $\left[\mathrm{M}-\mathrm{NH}_{3}\right]^{+}$fragment ion, respectively. This assignment is confirmed by good agreement of the mass spectrum recorded for II and the tabulated mass spectrum of sulfamic acid [10].

${ }^{1} \mathrm{H}$ NMR (DMSO- $\left.d_{6}, 400 \mathrm{MHz}\right), \delta, \operatorname{ppm}(J, \mathrm{~Hz})$ : 1.75 (s, 3H, NH- $\left.\underline{\mathrm{CH}}_{3}\right) 6.70(\mathrm{~s}, 1 \mathrm{H}, \mathrm{NH}), 7.12$ (s, $1 \mathrm{H}$, $\left.\mathrm{NH}^{+}\right), 7.30(\mathrm{~s}, 1 \mathrm{H}, \mathrm{NH}) .{ }^{13} \mathrm{C}$ NMR (DMSO-d ${ }_{6}$, $100 \mathrm{MHz}$ ), $\delta$, ppm: 22.89 (s, 1C, $\mathrm{CH}_{3}$ ).

The ${ }^{1} \mathrm{H}$ NMR spectrum (DMSO- $d_{6}, 400 \mathrm{MHz}$ ) exhibits signals for the methyl protons (singlet at $1.75 \mathrm{ppm}$ ) and signals of nonequivalent amino-group protons $(6.70$, $7.30 \mathrm{ppm})$ and ammonium protons $(7.12 \mathrm{ppm})$ broadened due to exchange with water. The proton-decoupled ${ }^{13} \mathrm{C}$ NMR spectrum shows a singlet for the methyl group (22.89 ppm).

The results of IR-spectroscopic study of product II and, for comparison, characteristic frequencies of crystalline thioacetamide, which were assigned resorting to published data [11], are presented in Table 1.

The $v(\mathrm{NH})$ vibrations are manifested as a broad intense band with peaks at 3400, 3260, 3140, 3070, and $2670 \mathrm{~cm}^{-1}$, which corresponds in the position and shape to the absorption of $-\mathrm{NH}_{2}$ and $-\mathrm{NH}_{3}^{+}$, groups involved in hydrogen bonding $[12,13]$. The absorption bands at about 1660 and $1608 \mathrm{~cm}^{-1}$ can be assigned to bending vibrations of these groups. The shoulder of the asymmetric band of $-\mathrm{CH}_{3}$ bending vibration at $1480 \mathrm{~cm}^{-1}$ is rather clear, whereas the $v(\mathrm{CH})$ bands at 2975-2900 $\mathrm{cm}^{-1}$ are superimposed by more intense absorption of $v\left(\mathrm{NH}_{2}\right)$ and $v\left(\mathrm{~N}^{+} \mathrm{H}_{3}\right)$ modes.

It should be emphasized that the IR spectrum of II does not contain the absorption band at $751 \mathrm{~cm}^{-1}$ with predominant contribution of $v(\mathrm{CS})$ vibrations typical of free thioamide.

The vibrational spectrum of the $\mathrm{NOSO}_{2}$ fragment can be interpreted proceeding from a tetrahedral structure: the symmetry decreases from $T_{d}\left(\mathrm{SO}_{4}^{2-}\right)$ to $C_{1}\left(\mathrm{NOSO}_{2}\right)$. According to the selection rules, the number of IR-active vibrations should increase from two to nine. Taking account of correlations [14] for sulfoxides and sulfones, it is assumed that in the spectrum of II, the absorption band at $1240 \mathrm{~cm}^{-1}$ should be assigned to asymmetric $\mathrm{S}=\mathrm{O}$ stretching vibrations. The $v_{s}(\mathrm{~S}=\mathrm{O})$ and $v(\mathrm{~S}-\mathrm{N})$ vibrations probably make a contribution to the strong absorption band at $1113 \mathrm{~cm}^{-1}$, which also includes the wagging bending vibrations of $\mathrm{NH}_{2}$ groups. 
Table 2. Electrical conductivity $10^{-3} \mathrm{M}$ solutions of II and $\mathrm{pH}$ of a $10^{-3} \mathrm{M}$ aqueous solution of II at $25^{\circ} \mathrm{C}$

\begin{tabular}{c|c|c|c|c|c}
\hline \multicolumn{5}{c|}{$\lambda, \Omega^{-1} \mathrm{~cm}^{2} \mathrm{~mol}^{-1}$} & $\mathrm{pH}$ \\
\hline $\mathrm{C}_{2} \mathrm{H}_{5} \mathrm{OH}$ & $\left(\mathrm{CH}_{3}\right)_{2} \mathrm{SO}$ & $\mathrm{CH}_{3} \mathrm{CN}$ & $\mathrm{CH}_{3} \mathrm{OH}$ & $\mathrm{H}_{2} \mathrm{O}$ & $\mathrm{H}_{2} \mathrm{O}$ \\
\hline 6.2 & 7.6 & 8.0 & 14.1 & 352.8 & 4.25 \\
\hline
\end{tabular}

The absorption band at $670 \mathrm{~cm}^{-1}$ can be identified as the $\mathrm{S}-\mathrm{O}$ stretching vibration of the ${ }^{-} \mathrm{O}-\mathrm{SO}_{2}$ fragment. The low-frequency shift of this band in the spectrum in question relative to the $870-810 \mathrm{~cm}^{-1}$ range [14] expected for the sulfoxide $\mathrm{HO}-\mathrm{SO}_{2}$ group is related, apparently, to strengthening of the sulfuroxygen single bond in the obtained product.

The compound nature of the medium-intensity band with a maximum at $\sim 618 \mathrm{~cm}^{-1}$ is due, judging by published data [14], to the overlap of the symmetrical bending vibrations of the $\mathrm{SO}_{2}$ and $\mathrm{NSO}$ fragments. The $\delta_{a s}\left(\mathrm{NSO}_{2}\right)$ and $\delta_{s}\left(\mathrm{NSO}_{2}\right)$ bending modes are responsible for the shoulder at $542 \mathrm{~cm}^{-1}$ and a medium-intensity band at $472 \mathrm{~cm}^{-1}$.

On the basis of elemental analysis data and spectroscopic studies, it can be stated that product II is methylammonium sulfamate monohydrate formed by the following route:

$$
\begin{gathered}
\mathrm{SO}_{2}+\mathrm{CH}_{3} \mathrm{C}(\mathrm{S}) \mathrm{NH}_{2}+\mathrm{H}_{2} \mathrm{O} \\
\stackrel{\mathrm{O}_{2}}{\longrightarrow}\left[\mathrm{CH}_{3} \mathrm{NH}_{3}\right]^{+}\left[\mathrm{OSO}_{2} \mathrm{NH}_{2}\right]^{-} \cdot \mathrm{H}_{2} \mathrm{O}+\mathrm{S} .
\end{gathered}
$$

The obtained compound melts at $117-118^{\circ} \mathrm{C}$, unlike the anhydrous salt $\left(\mathrm{mp}=91-93^{\circ} \mathrm{C}[8]\right)$. The solubility in water at $20^{\circ} \mathrm{C}$ is $32.48 \mathrm{wt} \%(5.60 \mathrm{~mol} \%)$. The molar electrical conductivity $\left(\lambda, \Omega^{-1} \mathrm{~cm}^{2} \mathrm{~mol}^{-1}\right)$ and $\mathrm{pH}$ of solutions of compound II are summarized in Table 2. Evidently, solutions of compound II in organic solvents are weak electrolytes (Table 2) [15]. The lower electrical conductivity values of a $10^{-3} \mathrm{M}$ aqueous solution of methylammonium sulfamate compared to that of a $10^{-3} \mathrm{M}$ aqueous solution of sulfamic acid $\left(\lambda \approx 384 \Omega^{-1} \mathrm{~cm}^{2} \mathrm{~mol}^{-1}\right.$ [16]) attest to complexation between $\mathrm{HOSO}_{2} \mathrm{NH}_{2}$ and $\mathrm{CH}_{3} \mathrm{NH}_{2}$ through $\mathrm{H}$-bonding.
Thus, the developed method provides a route to sulfamic acid derivatives requiring mild conditions, low temperature, and no use of corrosive reagents. It is of interest that the reaction of the oxygen thioacetamide analog with sulfur dioxide in an aqueous solution in a similar situation is accompanied by condensation of $\mathrm{CH}_{3} \mathrm{C}(\mathrm{O}) \mathrm{NH}_{2}$ giving cyclic $o$-quinoid compound [17].

\section{REFERENCES}

1. J. Y. Winum, A. Scozzafava, J. L. Montero, and C. T. Supuran, Med. Res. Rev. 25 (2), 186 (2005).

2. US Patent $7183246,2007$.

3. US Patent 5186946, 1993.

4. S. D. Mitragotri, D. M. Pore, U. V. Desai, and P. P. Wadgaonkar, Catal. Commun. 9 (9), 1822 (2008).

5. Bo Wang, Yanlong Gu, Cheng Luo, et al., Tetrahedron Lett. 45 (17), 3369 (2005).

6. Min Xia, and Yue-dong Lu, Heteroatom. Chem., 18 (4), 354 (2006).

7. Chemical Encyclopedia, Ed. by N. S. Zefirov (Bol'shaya Rossiiskaya Entsiklopediya, Moscow, 1995), vol. 4 [in Russian].

8. L. Goodson, J. Am. Chem. Soc. 69 (5), 1230 (1947).

9. V. A. Klimova, Basic Methods of Analysis of Organic Compounds (Khimiya, Moscow, 1975) [in Russian].

10. http://webbook.nist.gov/cgi/cbook.cgi?ID=C5329146\& Mask=200\#Mass-Spec.

11. Yu. Ya. Kharitonov, A. Yu. Tsivadze, A. N. Smirnov, and G. V. Tsintsadze, Koord. Khim. 1 (5), 641 (1975).

12. K. Nakamoto, Infrared and Raman Spectra of Inorganic and Coordination Compounds (Wiley, New York, 1986; Mir, Moscow, 1991).

13. K. Nakanishi, Infrared Absorption Spectroscopy (Tokyo, 1962; Mir, Moscow, 1965).

14. E. Pretsch, P. Bühlmann, and C. Affolter, Structure Determination of Organic Compounds-Tables of Spectral Data (Springer, Berlin, 2000; Mir/BINOM, Moscow, 2006).

15. W. J. Geary, Coord. Chem. Rev. 7 (1), 82 (1971).

16. A. Avranas, V. Terzoglou, and N. Papadopoulos, Collect. Czech. Chem. Commun. 57 (8), 1613 (1992).

17. R. E. Khoma, A. V. Mazepa, A. A. Shestaka, et al., Zh. Obshch. Khim. 79 (6), 1048 (2009) [Russ. J. Gen. Chem. 79 (6), 1223 (2009)]. 